\title{
Optimal Binding of Acetylene to a Nitro-Decorated Metal-Organic Framework
}

Thien D. Duong, ${ }^{\dagger}$ Sergey A. Sapchenko, ${ }^{\dagger, \perp, \ddagger}$ Ivan da Silva, ${ }^{\ddagger}$ Harry G. W. Godfrey, ${ }^{\dagger}$ Yongqiang Cheng, ${ }^{\S}$ Luke L. Daemen, ${ }^{\S}$ Pascal Manuel, ${ }^{\ddagger}$ Anibal J. Ramirez-Cuesta, ${ }^{\S}$ Sihai Yang, ${ }^{*}, \dagger$ and Martin Schröder ${ }^{*}, \uparrow^{+}$

${ }^{\dagger}$ School of Chemistry, University of Manchester, Oxford Road, Manchester M13 9PL, United Kingdom

${ }^{\perp}$ Nikolaev Institute of Inorganic Chemistry, Siberian Branch of the Russian Academy of Sciences, Acad. Lavrentieva Avenue, 3, 630090 Novosibirsk, Russia

${ }^{\ddagger}$ Faculty of Natural Sciences, Novosibirsk State University, Pirogova Street, 2, 630090 Novosibirsk, Russia

${ }^{\ddagger}$ ISIS Facility, STFC Rutherford Appleton Laboratory, Chilton, Oxfordshire OX11 0QX, United Kingdom

${ }^{\S}$ Oak Ridge National Laboratory, Oak Ridge, Tennessee 37831, United States

\section{Supporting Information}

ABSTRACT: We report the first example of crystallographic observation of acetylene binding to $-\mathrm{NO}_{2}$ groups in a metal-organic framework (MOF). Functionalization of MFM-102 with $-\mathrm{NO}_{2}$ groups on phenyl groups leads to a $15 \%$ reduction in BET surface area in MFM-102$\mathrm{NO}_{2}$. However, this is coupled to a $28 \%$ increase in acetylene adsorption to $192 \mathrm{~cm}^{3} \mathrm{~g}^{-1}$ at $298 \mathrm{~K}$ and 1 bar, comparable to other leading porous materials. Neutron diffraction and inelastic scattering experiments reveal the role of $-\mathrm{NO}_{2}$ groups, in cooperation with open metal sites, in the binding of acetylene in MFM-102- $\mathrm{NO}_{2}$.

A cetylene is an important chemical for the production of polymers and other advanced materials. ${ }^{1}$ However, it is highly explosive and cannot be compressed beyond 2 atm at room temperature, thus making its storage and transport a challenge. Acetylene storage is achieved currently by dissolving acetylene gas in acetone under high pressure (equivalent to $\sim 10 \mathrm{~atm})$ in a heavy-duty tank filled with porous materials, such as firebrick. ${ }^{2}$ This enables the transport of acetylene in liquid form. However, such processes are not only costly but also limit the purity of stored acetylene to $295 \%$, making it unsuitable for many applications unless a secondary purification process is applied. Porous metal-organic frameworks (MOFs) are emerging sorbents for a variety of gases owing to their high porosity, well-defined pore size, their design flexibility and ability to incorporate active binding sites. ${ }^{3}$ Recently, there has been an increasing interest in the study of MOFs for acetylene storage, ${ }^{4}$ and the introduction of organic functional groups is an efficient approach to increase the gas binding within pores. MOFs incorporating $-\mathrm{OH}^{5}-\mathrm{NH}_{2}{ }^{6}$ $-\mathrm{CONH}-{ }^{7}-\mathrm{C} \equiv \mathrm{C}-{ }^{8}, \mathrm{R}-\mathrm{CO}-\mathrm{R},{ }^{9}-\mathrm{R},{ }^{10}-\mathrm{OR},{ }^{11}$ pyridine-, ${ }^{12}$ pyrimidine-, ${ }^{13}$ pyrazine-, ${ }^{13}$ pyridazine-, ${ }^{13}$ and naphthalene ${ }^{14}$ groups have been tested for acetylene adsorption. However, molecular insights into the precise role of these moieties on the binding of acetylene is largely lacking, thus restricting the design of improved materials.

Acetylene is relatively electron-rich due to its triple bond, and we argued that MOFs incorporating electro-positive or electron withdrawing groups would be a promising approach to facilitate $\mathrm{C}_{2} \mathrm{H}_{2}$ binding. The nitro group $\left(-\mathrm{NO}_{2}\right)$ is one of the most powerful electron-withdrawing groups. However, the direct visualization of gas binding to $-\mathrm{NO}_{2}$ groups in MOFs has not been reported to date and adsorption of acetylene in $\mathrm{NO}_{2}$-decorated MOFs remains unexplored. ${ }^{15}$ Here, we report the study of acetylene adsorption in a family of four isostructural MOFs (the MFM-102 series) bearing different functional groups, including nitro, amine, and alkane groups. The selection of these functional groups gives a wide coverage in terms of their electron donating and withdrawing power. We found that functionalization of the parent MFM-102 with $\mathrm{NO}_{2}$ groups leads to a $16 \%$ reduction in the $\mathrm{BET}$ surface area in MFM-102- $\mathrm{NO}_{2}$, but a $28 \%$ improvement in acetylene adsorption to $192 \mathrm{~cm}^{3} \mathrm{~g}^{-1}$ at $298 \mathrm{~K}$ and $1 \mathrm{bar}$, comparable to the leading materials for acetylene storage. The binding domains for adsorbed acetylene molecules in MFM-102- $\mathrm{NO}_{2}$ have been studied by in situ neutron powder diffraction and inelastic scattering experiments. In comparison, other functional groups (i.e., amine and alkane groups in MFM-102- $\mathrm{NH}_{2}$ and MFM-111, respectively) have neutral or detrimental effects on acetylene adsorption compared to MFM-102- $\mathrm{NO}_{2}$. Importantly, we describe the first example of observation of direct binding of acetylene molecules to the $-\mathrm{NO}_{2}$ groups in a MOF material, leading to the optimal adsorption of this substrate.

$\mathrm{H}_{4} \mathrm{~L}^{1}$ and $\mathrm{H}_{4} \mathrm{~L}^{2}$ were synthesized using our previously reported methods. ${ }^{16}$ Introduction of nitro and amine groups to $\mathrm{H}_{4} \mathrm{~L}^{1}$ yielded $\mathrm{H}_{4} \mathrm{~L}^{3}$ and $\mathrm{H}_{4} \mathrm{~L}^{4}$, respectively. Single crystals of MFM-102, MFM-111, MFM-102- $\mathrm{NO}_{2}$, and MFM-102-NH were synthesized from $\mathrm{Cu}\left(\mathrm{NO}_{3}\right)_{2} \cdot 6 \mathrm{H}_{2} \mathrm{O}$ and the corresponding ligand in DMF or DMF/DMSO under solvothermal conditions. Single crystal X-ray diffraction analysis indicated that all these MOFs are iso-structural, crystallize in the hexagonal space group $R \overline{3} m$, and adopt a NbO-type structure (Figure 1).

The crystal structure of MFM-102- $\mathrm{NO}_{2}$ is described here in detail. Two $\mathrm{Cu}(\mathrm{II})$ ions are bridged by four carboxylate groups

Received: August 8, 2018

Published: October 4, 2018 


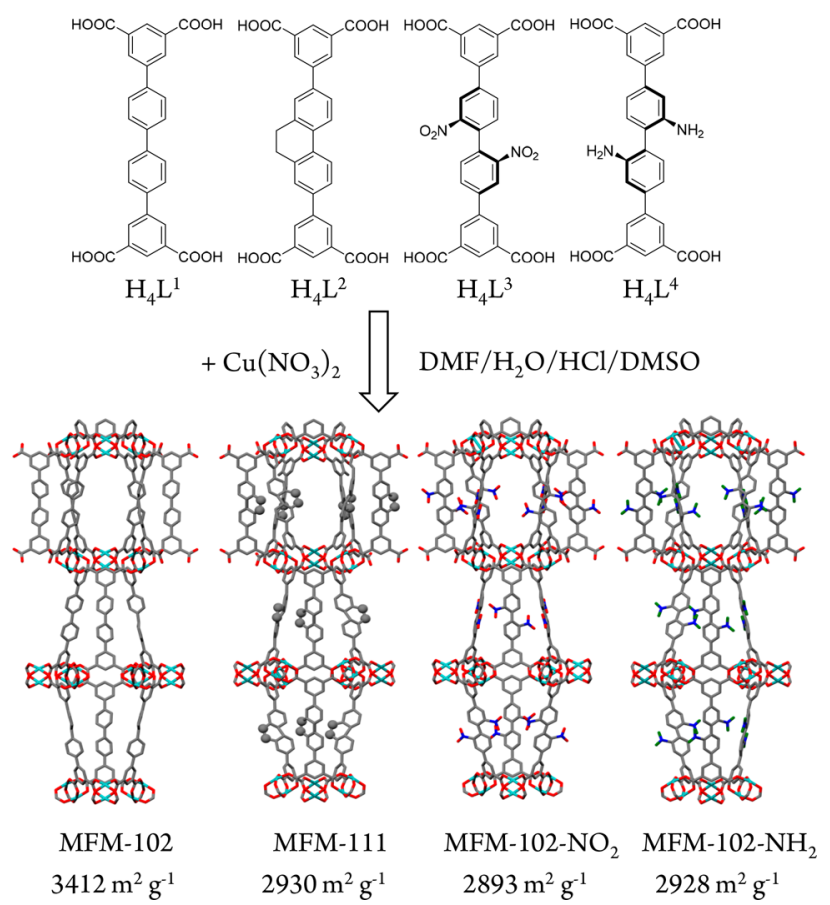

Figure 1. Views of organic linkers and the crystal structure for MFM102, MFM-111, MFM-102-NO $\mathrm{NO}_{2}$, and MFM-102- $\mathrm{NH}_{2}$. The BET surface area for each MOF is shown at the bottom (C, dark gray; $\mathrm{O}$, red; $\mathrm{N}$, blue; $\mathrm{Cu}$, turquoise; all coordinated waters and hydrogen atoms are omitted for clarity, except for the hydrogen atoms on the $-\mathrm{NH}_{2}$ group).

to form a $\left[\mathrm{Cu}_{2}(\mathrm{OOCR})_{4}\left(\mathrm{OH}_{2}\right)_{2}\right]$ paddlewheel node $\left\{\mathrm{Cu}_{2}\right\}$. This serves as a 4-connected node that is further linked to other 4-connected nodes to construct a 3D NbO-type open structure. All these MOFs are constructed by the alternative packing of 2 types of metal-ligand cages (A and B) (Figure 1). Cage $\mathrm{A}$, constructed by six linkers and six $\left\{\mathrm{Cu}_{2}\right\}$ paddlewheels, has a cylindrical shape with a diameter of $14 \AA$ and length of 19 $\AA$. Cage B (length of $32 \AA$ ) has a shuttle-shape with $12\left\{\mathrm{Cu}_{2}\right\}$ paddlewheels residing at the vertices and 6 ligands on the faces. It is noteworthy that the cages in MFM-111, MFM-102- $\mathrm{NH}_{2}$, and MFM-102- $\mathrm{NO}_{2}$ are decorated with alkane, $-\mathrm{NH}_{2}$ and $-\mathrm{NO}_{2}$ groups, respectively, pointing into both cages, thus providing additional binding sites for gas molecules. Phase purity of each complex has been confirmed by PXRD data (see SI). The coordinated water molecules and solvent molecules in the pores can be removed under heating to generate open $\mathrm{Cu}$ (II) sites in the desolvated materials.

$\mathrm{N}_{2}$ isotherms at $77 \mathrm{~K}$ confirm that desolvated MFM-102, MFM-111, MFM-102- $\mathrm{NH}_{2}$, and MFM-102- $\mathrm{NO}_{2}$ show BET surface areas of 3412, 2930, 2928, and $2893 \mathrm{~m}^{2} \mathrm{~g}^{-1}$, respectively (Figures 1,2) with introduction of functional groups leading to reduction in porosity. These values are higher than other reported MOFs with NbO-topology such as NJU-Bai-17 $\left(2423 \mathrm{~m}^{2} \mathrm{~g}^{-1}\right),{ }^{17}$ UTSA-88 $\left(1771 \mathrm{~m}^{2} \mathrm{~g}^{-1}\right),{ }^{18}$ and ZJU-7 $\left(2209 \mathrm{~m}^{2} \mathrm{~g}^{-1}\right){ }^{1}$

Uptakes of $\mathrm{C}_{2} \mathrm{H}_{2}$ at $273 \mathrm{~K}$ and 1 bar were recorded as 292 , 261, 251, and $241 \mathrm{~cm}^{3} \mathrm{~g}^{-1}$ for MFM-102-NO $\mathrm{NO}_{2}$ MFM-102$\mathrm{NH}_{2}$, MFM-102, and MFM-111, respectively (Figure S8). Significantly, the $\mathrm{C}_{2} \mathrm{H}_{2}$ uptake of MFM-102- $\mathrm{NO}_{2}\left(292 \mathrm{~cm}^{3}\right.$ $\mathrm{g}^{-1}$ ) is among the best-performing MOFs under the same conditions (Table S3), such as NJU-Bail7 $\left(295 \mathrm{~cm}^{3} \mathrm{~g}^{-1}\right),{ }^{17}$ MFM-188a $\left(297 \mathrm{~cm}^{3} \mathrm{~g}^{-1}\right),{ }^{7}$ and FJI-H8 $\left(277 \mathrm{~cm}^{3} \mathrm{~g}^{-1}\right){ }^{20}$
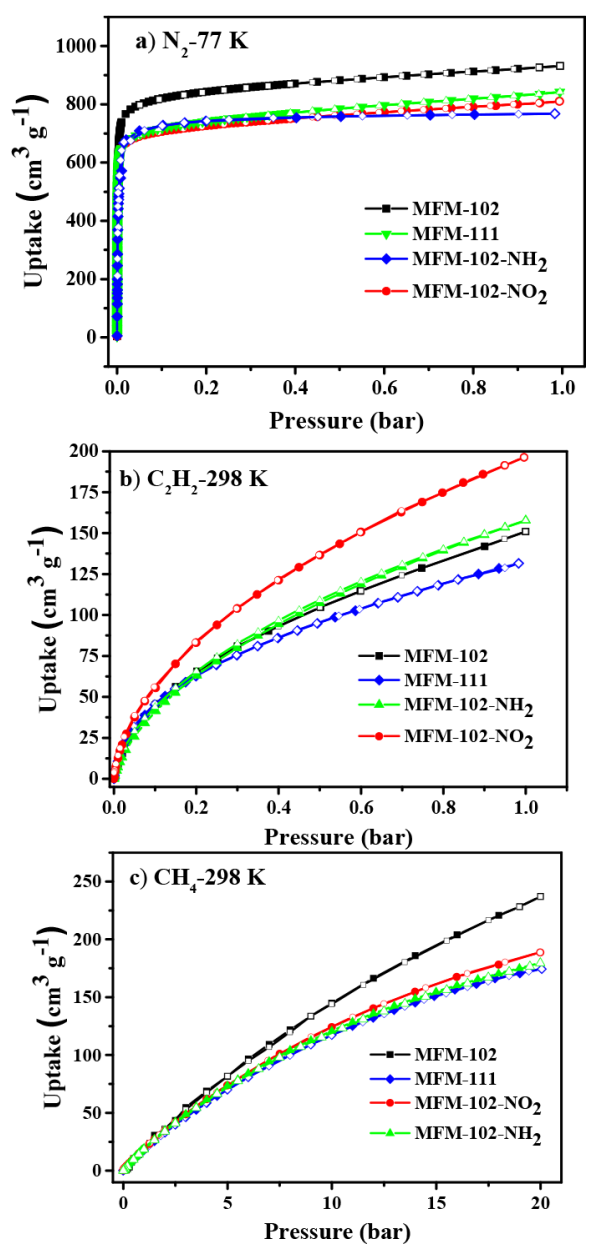

Figure 2. Adsorption isotherms for desolvated MFM-102, MFM-111, MFM-102- $\mathrm{NO}_{2}$, and MFM-102- $\mathrm{NH}_{2}$. (a) $\mathrm{N}_{2}$ at $77 \mathrm{~K}$; (b) $\mathrm{C}_{2} \mathrm{H}_{2}$ at $298 \mathrm{~K}$; (c) $\mathrm{CH}_{4}$ at $298 \mathrm{~K}$. Solid and open symbols represent adsorption and desorption, respectively.

Interestingly, although the introduction of $\mathrm{NO}_{2}$-groups to MFM-102 leads to a $15 \%$ reduction of BET surface area in MFM-102- $\mathrm{NO}_{2}$, it results in a $28 \%$ enhancement in $\mathrm{C}_{2} \mathrm{H}_{2}$ adsorption under ambient conditions, demonstrating the positive effect of $\mathrm{NO}_{2}$-groups on $\mathrm{C}_{2} \mathrm{H}_{2}$ binding. With similar BET surface areas, MFM-102- $\mathrm{NO}_{2}, \mathrm{MFM}-102-\mathrm{NH}_{2}$, and MFM-111 provide an excellent platform to directly examine the role of functional group on $\mathrm{C}_{2} \mathrm{H}_{2}$ adsorption. Compared to the parent MFM-102, introduction of the amine group shows a small increase (5.3\%) in adsorption of $\mathrm{C}_{2} \mathrm{H}_{2}$, while the alkane group leads a moderate reduction $(-12 \%)$ in $\mathrm{C}_{2} \mathrm{H}_{2}$ adsorption. The isosteric heats of $\mathrm{C}_{2} \mathrm{H}_{2}$ adsorption $\left(Q_{t}\right)$ for these MOFs are around 31 to $33 \mathrm{~kJ} \mathrm{~mol}^{-1}$, comparable to reported MOFs with open $\mathrm{Cu}(\mathrm{II})$ sites (Table S3). The $Q_{t}$ plots shows little variation as a function of uptake, indicating the presence of cooperativity of host-guest and guest-guest binding. ${ }^{21}$

To establish the role of these functional groups on $\mathrm{C}_{2} \mathrm{H}_{2}$ binding, adsorption of $\mathrm{CH}_{4}$, as a noninteracting gas probe, was also measured. At $298 \mathrm{~K}$ and $20 \mathrm{bar}, \mathrm{MFM}-102$ shows a $\mathrm{CH}_{4}$ uptake of $236 \mathrm{~cm}^{3} \mathrm{~g}^{-1}$, which is higher than that for MFM-102$\mathrm{NO}_{2}$, MFM-102- $\mathrm{NH}_{2}$, and MFM-111 (188, 179, and $173 \mathrm{~cm}^{3}$ $\mathrm{g}^{-1}$, respectively). The trend in uptake of $\mathrm{CH}_{4}$ is consistent with the variation of BET surface areas of these materials, and suggests potential binding interactions between the $-\mathrm{NO}_{2}$ functional group and unsaturated $\mathrm{C}_{2} \mathrm{H}_{2}$. 
Six independent binding sites ( $\mathrm{I}$ to $\mathrm{VI}$ ) for adsorbed $\mathrm{C}_{2} \mathrm{D}_{2}$ molecules in MFM-102- $\mathrm{NO}_{2}$ have been determined by in situ neutron powder diffraction (NPD) (Figure 3). Sites I and II

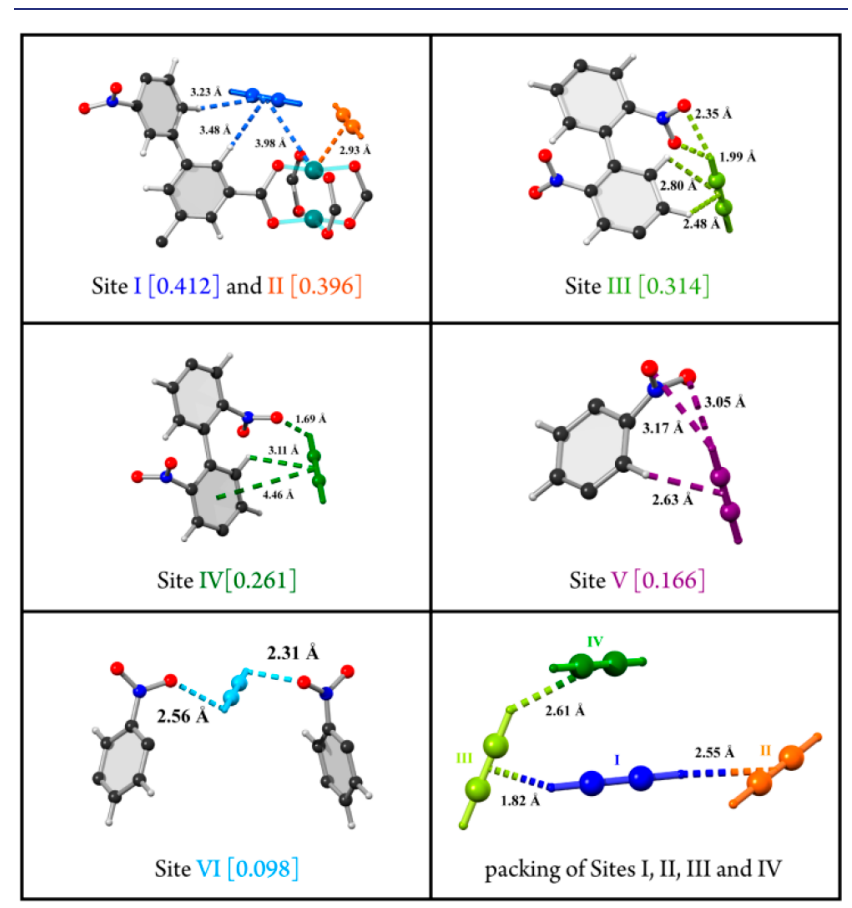

Figure 3. View of the binding sites for adsorbed $\mathrm{C}_{2} \mathrm{D}_{2}$ molecules in MFM-102- $\mathrm{NO}_{2}$. (C, dark gray; $\mathrm{O}$, red; $\mathrm{N}$, blue; $\mathrm{Cu}$, turquoise and $\mathrm{C}_{2} \mathrm{D}_{2}$ molecules at site I (light blue), site II (orange), site III (light green), site IV (dark green), site V (purple) and site VI (sapphire).

(occupancies of 0.41 and 0.40 , respectively) are located at the open $\mathrm{Cu}$ (II) sites with a side-on interaction between the $\mathrm{C} \equiv \mathrm{C}$ bond and $\mathrm{Cu}(\mathrm{II})[\mathrm{Cu} \cdots \mathrm{C} \equiv \mathrm{C}($ centroid $)=3.98(5)$ and 2.93(8) Å for site I and II, respectively]. Interestingly, sites I and II have very different bonding distance to the open $\mathrm{Cu}$ (II) site. A closer examination revealed that site I also forms supramolecular interactions to two aromatic $-\mathrm{CH}$ groups from two adjacent phenyl rings $[-\mathrm{CH} \cdots \mathrm{C} \equiv \mathrm{C}($ centroid $)=3.23(2)$, $3.48(3) \AA]$ and becomes the most populated location owing to this cooperativity between sites. Site III (occupancy 0.31 ) is stabilized by a combination of three types of interactions to the host: (i) hydrogen bonds between the $\mathrm{D}\left(\delta^{+}\right)$of $\mathrm{C}_{2} \mathrm{D}_{2}$ molecules and $\mathrm{O}\left(\delta^{-}\right)$center of the $-\mathrm{NO}_{2}$ group $[\mathrm{D} \cdots \mathrm{O}=$ 1.99(9), 2.35(6) $\AA]$; (ii) supramolecular interactions between the $\mathrm{C} \equiv \mathrm{C}$ bond and the $-\mathrm{CH}$ group on adjacent $\mathrm{NO}_{2}$ decorated phenyl rings $[-\mathrm{CH} \cdots \mathrm{C} \equiv \mathrm{C}($ centroid $)=2.47(9)$, 2.80(4) $\AA$ ]; (iii) intermolecular dipole interactions between $\pi$ electrons in the $\mathrm{C} \equiv \mathrm{C}$ bond (site III) and $\mathrm{D}$ atoms of $\mathrm{C}_{2} \mathrm{D}_{2}$ at site IV. Site IV (occupancy 0.26) is also stabilized by hydrogen bonds between $\mathrm{C}_{2} \mathrm{D}_{2}$ molecules and $-\mathrm{NO}_{2}$ groups $\left[\mathrm{D} \cdots \mathrm{O}_{\mathrm{NO} 2}\right.$ $=1.69(2) \AA]$ and a $-\mathrm{CH}$ bond of the $\mathrm{NO}_{2}$-decorated phenyl ring $[-\mathrm{CH} \cdots \mathrm{C} \equiv \mathrm{C}($ centroid $)=3.11(4) \AA]$. Moreover, there is a weak $\pi \cdots \pi$ interaction between $\mathrm{C} \equiv \mathrm{C}$ bond of $\mathrm{C}_{2} \mathrm{D}_{2}(\mathrm{IV})$ and the $\mathrm{NO}_{2}$-decorated phenyl ring [ring centroid $\cdots \mathrm{C} \equiv \mathrm{C}$ $($ centroid $)=4.46(8) \AA]$. Site V (occupancy $=0.16)$ is at the window between the cylindrical and spherical cages involving similar side-on mode interactions with the $-\mathrm{CH}$ group of the $\mathrm{NO}_{2}$-decorated phenyl ring $[-\mathrm{CH} \cdots \mathrm{C} \equiv \mathrm{C}($ centroid $)=$ 2.63(5) $\AA$ ] and the hydrogen bond to the $-\mathrm{NO}_{2}$ group $[\mathrm{D} \cdots$ $\left.\mathrm{ONO}_{2}=3.05(10), 3.17(7) \AA\right]$. Site VI (occupancy $=0.09$ ) is located in the center of the elongated cage, interacting directly with the $-\mathrm{NO}_{2}$ group from three surrounding ligands with $\mathrm{D} \cdots$ $\mathrm{ONO}_{2}$ distances ranging from 2.37(1) to 2.56(3) Å. Overall, $\mathrm{C}_{2} \mathrm{D}_{2}$ molecules at sites III-VI are all directly associated with the $-\mathrm{NO}_{2}$ groups in the pore, confirming the positive effect of $-\mathrm{NO}_{2}$ group in achieving optimal acetylene binding.

The binding dynamics of $\mathrm{C}_{2} \mathrm{H}_{2}$-loaded MFM-102- $\mathrm{NO}_{2}$ were also studied by in situ inelastic neutron scattering (INS). The INS spectrum of bare MOF shows excellent agreement with that obtained from DFT calculations, thus allowing assignment of vibrational modes (Figure $\mathrm{S} 12$ ). The INS spectrum of $\mathrm{C}_{2} \mathrm{H}_{2}-$ loaded MFM-102- $\mathrm{NO}_{2}$ shows a significant increase in intensity (Figures 4 and S11). The INS peaks at 80 and $95 \mathrm{meV}$

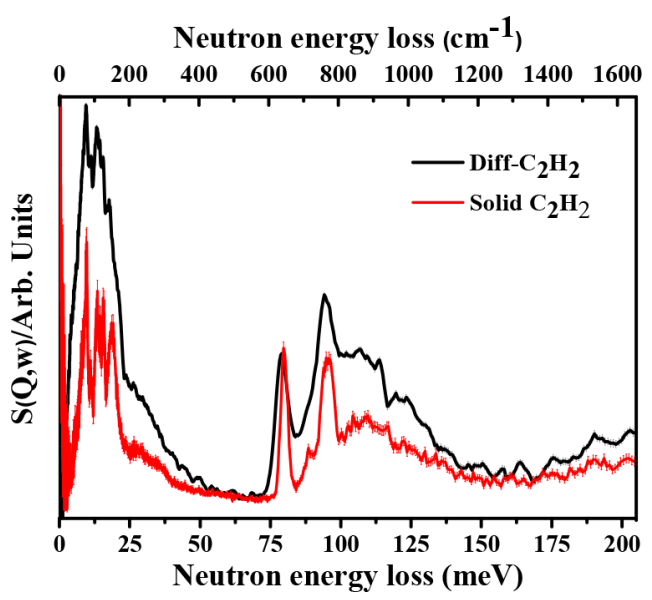

Figure 4. INS spectra for MFM-102- $\mathrm{NO}_{2}$ with $\mathrm{C}_{2} \mathrm{H}_{2}$ loading. Comparison of difference INS plots derived by subtracting INS spectra for $\mathrm{C}_{2} \mathrm{H}_{2}$-loaded MFM-102- $\mathrm{NO}_{2}$ and bare MFM-102- $\mathrm{NO}_{2}$ spectra (black), with condensed $\mathrm{C}_{2} \mathrm{H}_{2}$ in the solid state (red).

(assigned as the asymmetric and symmetric $\mathrm{C}-\mathrm{H}$ bending mode of $\mathrm{C}_{2} \mathrm{H}_{2}$, respectively) show significant broadening on adsorption of $\mathrm{C}_{2} \mathrm{H}_{2}$ with the appearance of shoulders on both sides and a shift to lower energy. In addition, the translational modes of $\mathrm{C}_{2} \mathrm{H}_{2}$ molecules, represented by the INS peaks at low energy region (below $25 \mathrm{meV}$ ), show restricted motion on adsorption, with adsorbed $\mathrm{C}_{2} \mathrm{H}_{2}$ molecules well-ordered in the pore as these peaks all shift to lower energy but still remain a 3fold feature as found in solid $\mathrm{C}_{2} \mathrm{H}_{2}$. Moreover, in the difference spectra, peaks at 164 and $189 \mathrm{meV}$ (Figure S12) develop upon inclusion of $\mathrm{C}_{2} \mathrm{H}_{2}$ molecules in the pore, and this enhancement of both symmetrical and antisymmetrical stretching modes of $-\mathrm{NO}_{2}$ groups is consistent with the formation of host-guest interactions between the $-\mathrm{NO}_{2}$ groups and adsorbed $\mathrm{C}_{2} \mathrm{H}_{2}$ molecules. Overall, these results are highly consistent with the crystallographic studies showing various binding sites (I-VI) of $\mathrm{C}_{2} \mathrm{D}_{2}$ and the strong interaction between the $-\mathrm{NO}_{2}$ group and $\mathrm{C}_{2} \mathrm{D}_{2}$ molecules (sites III-VI) in the pore of MFM-102$\mathrm{NO}_{2}$.

Achieving optimal gas adsorption and binding in porous materials requires integration of high porosity and appropriate binding sites. However, introduction of functional groups naturally reduces the porosity of decorated MOFs, leading to a trade-off between these two factors. In this study, the effect of amine, alkane and nitro groups on adsorption of $\mathrm{C}_{2} \mathrm{H}_{2}$ has been examined in a family of isostructural MOFs showing high BET surface areas. The first example of binding between electron-rich $\mathrm{C}_{2} \mathrm{H}_{2}$ molecules and electron withdrawing $-\mathrm{NO}_{2}$ 
groups in the MOF, MFM-102- $\mathrm{NO}_{2}$, at crystallographic resolution has been established. The combination of high BET surface area, high density of open $\mathrm{Cu}(\mathrm{II})$ sites and accessible $\mathrm{NO}_{2}$-groups leads to excellent adsorption capacity of $\mathrm{C}_{2} \mathrm{H}_{2}$ in MFM-102- $\mathrm{NO}_{2}$, making it one of the best-performing acetylene adsorbents to date.

\section{ASSOCIATED CONTENT}

\section{S Supporting Information}

The Supporting Information is available free of charge on the ACS Publications website at DOI: 10.1021/jacs.8b08504.

Synthesis procedures, characterization, and additional analysis of crystal structures (PDF)

Single crystal data of MFM-102- $\mathrm{NO}_{2}$ (CIF)

Single crystal data of MFM-102- $\mathrm{NH}_{2}$ (CIF)

Single crystal data of activated MFM-102- $\mathrm{NO}_{2}$ (CIF)

Single crystal data of $\mathrm{C}_{2} \mathrm{D}_{2}$-loaded MFM-102- $\mathrm{NO}_{2}$ (CIF)

\section{AUTHOR INFORMATION}

\section{Corresponding Authors}

*Sihai.Yang@manchester.ac.uk

*M.Schroder@manchester.ac.uk

\section{ORCID}

Sihai Yang: 0000-0002-1111-9272

Martin Schröder: 0000-0001-6992-0700

\section{Notes}

The authors declare no competing financial interest.

Single crystal data of MFM-102- $\mathrm{NO}_{2}$ and MFM-102- $\mathrm{NH}_{2}$ are deposited at Cambridge Crystallographic Data Centre (CCDC) as 1857304 and 1857305, respectively, with NPD data deposited as 1857872 and 1857873 for $\mathrm{C}_{2} \mathrm{D}_{2}$-loaded MFM-102- $\mathrm{NO}_{2}$ and activated MFM-102- $\mathrm{NO}_{2}$, respectively.

\section{ACKNOWLEDGMENTS}

We thank EPSRC (EP/I011870, EP/P001386, EP/K038869), ERC (AdG 226593) and University of Manchester for funding. We thank ISIS/STFC and ORNL for access to Beamlines WISH and VISION, respectively. The computing resources were made available through the VirtuES and ICEMAN projects, funded by Laboratory Directed Research and Development program at ORNL. We thank D. Rizzo and Dr. Iñigo J. Victórica-Yrezábal for helpful discussions.

\section{REFERENCES}

(1) Stang, P. J.; Diederich, F. Modern Acetylene Chemistry; Wiley$\mathrm{VCH}, 2008$.

(2) Schobert, H. Chem. Rev. 2014, 114, 1743.

(3) Lu, W.; Wei, Z.; Gu, Z.-Y.; Liu, T.-F.; Park, J.; Park, J.; Tian, J.; Zhang, M.; Zhang, Q.; Gentle, T., III; Bosch, M.; Zhou, H.-C. Chem. Soc. Rev. 2014, 43, 5561.

(4) (a) Xu, H.; Cai, J.; Xiang, S.; Zhang, Z.; Wu, C.; Rao, X.; Cui, Y.; Yang, Y.; Krishna, R.; Chen, B.; Qian, G. J. Mater. Chem. A 2013, 1, 9916. (b) Xiang, S.; Zhou, W.; Zhang, Z.; Green, M. A.; Liu, Y.; Chen, B. Angew. Chem., Int. Ed. 2010, 49, 4615. (c) Liu, K.; Ma, D.; Li, B.; Li, Y.; Yao, K.; Zhang, Z.; Han, Y.; Shi, Z. J. Mater. Chem. A 2014, 2, 15823.

(5) Duan, X.; Wang, H.; Ji, Z.; Cui, Y.; Yang, Y.; Qian, G. J. Solid State Chem. 2016, 241, 152.

(6) Cai, J.; Wang, H.; Wang, H.; Duan, X.; Wang, Z.; Cui, Y.; Yang, Y.; Chen, B.; Qian, G. RSC Adv. 2015, 5, 77417.
(7) Moreau, F.; da Silva, I.; Al Smail, N. H.; Easun, T. L.; Savage, M.; Godfrey, H. G. W.; Parker, S. F.; Manuel, P.; Yang, S.; Schröder, M. Nat. Commun. 2017, 8, 14085.

(8) Hu, Y.; Xiang, S.; Zhang, W.; Zhang, Z.; Wang, L.; Bai, J.; Chen, B. Chem. Commun. 2009, 7551.

(9) Duan, X.; Zhang, Q.; Cai, J.; Cui, Y.; Wu, C.; Yang, Y.; Qian, G. Microporous Mesoporous Mater. 2014, 190, 32.

(10) Wang, Y.; He, M.; Tian, Z.; Zhong, H.; Zhu, L.; Zhang, Y.; Zhang, X.; Chen, D.-L.; He, Y. Dalton Trans 2018, 47, 2444.

(11) Chen, F.; Wang, Y.; Bai, D.; He, M.; Gao, X.; He, Y. J. Mater. Chem. A 2018, 6, 3471.

(12) Rao, X.; Cai, J.; Yu, J.; He, Y.; Wu, C.; Zhou, W.; Yildirim, T.; Chen, B.; Qian, G. Chem. Commun. 2013, 49, 6719.

(13) Song, C.; Jiao, J.; Lin, Q.; Liu, H.; He, Y. Dalton Trans 2016, $45,4563$.

(14) Chen, F.; Bai, D.; Jiang, D.; Wang, Y.; He, Y. Dalton Trans 2017, 46, 11469.

(15) (a) Zhang, M.; Wang, Q.; Lu, Z.; Liu, H.; Liu, W.; Bai, J. CrystEngComm 2014, 16, 6287. (b) Cmarik, G. E.; Kim, M.; Cohen, S. M.; Walton, K. S. Langmuir 2012, 28, 15606. (c) Maity, D. K.; Halder, A.; Bhattacharya, B.; Das, A.; Ghoshal, D. Cryst. Growth Des. 2016, 16, 1162. (d) Mowat, J. P. S.; Miller, S. R.; Griffin, J. M.; Seymour, V. R.; Ashbrook, S. E.; Thompson, S. P.; Fairen-Jimenez, D.; Banu, A.-M.; Düren, T.; Wright, P. A. Inorg. Chem. 2011, 50, 10844. (e) McDonald, K. A.; Ko, N.; Noh, K.; Bennion, J. C.; Kim, J.; Matzger, A. Chem. Commun. 2017, 53, 7808.

(16) (a) Lin, X.; Telepeni, I.; Blake, A. J.; Dailly, A.; Brown, C. M.; Simmons, J. M.; Zoppi, M.; Walker, G. S.; Thomas, K. M.; Mays, T. J.; Hubberstey, P.; Champness, N. R.; Schröder, M. J. Am. Chem. Soc. 2009, 131, 2159. (b) Yang, S.; Lin, X.; Dailly, A.; Blake, A. J.; Hubberstey, P.; Champness, N. R.; Schröder, M. Chem. - Eur. J. 2009, $15,4829$.

(17) Zhang, M.; Li, B.; Li, Y.; Wang, Q.; Zhang, W.; Chen, B.; Li, S.; Pan, Y.; You, X.; Bai. Chem. Commun. 2016, 52, 7241.

(18) Chang, G.; Li, B.; Wang, H.; Bao, Z.; Yildirim, T.; Yao, Z.; Xiang, S.; Zhou, W.; Chen, B. Chem. Commun. 2015, 51, 14789.

(19) Duan, X.; Wang, H.; Cui, Y.; Yang, Y.; Wang, Z.; Chen, B.; Qian, G. RSC Adv. 2015, 5, 84446.

(20) Pang, J.; Jiang, F.; Wu, M.; Liu, C.; Su, K.; Lu, W.; Yuan, D.; Hong, M. Nat. Commun. 2015, 6, 7575.

(21) Vaidhyanathan, R.; Iremonger, S. S.; Shimizu, G. K. H.; Boyd, P. G.; Alavi, S.; Woo, T. K. Science 2010, 330, 650. 